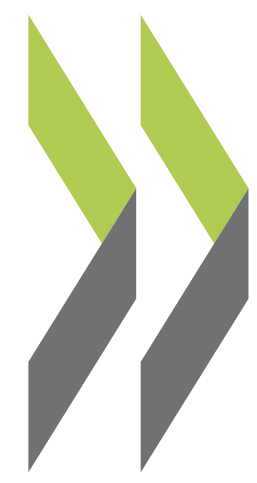

PEB Exchange, Programme on Educational Building 2004/05

\title{
A Building Development Plan at Laval University, \\ Quebec
}

\section{Gilles Daoust}




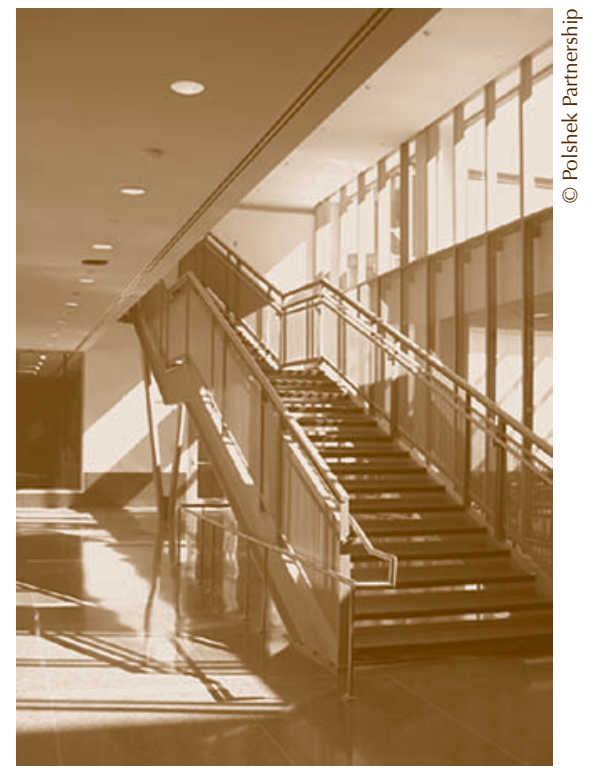

The common areas (cafeteria, entrance hall, library, gym) are at ground floor and basement levels. This means that the central courtyard begins at the third level, creating a spacious open area in the midst of a building with a total floor area of $16000 \mathrm{~m}^{2}$. Every square meter has been put to good use, and a running track has even been installed on the roof of the building. An auditorium, which will be open to the public and will be used for various performances and events, should enable both the Lycée and the local French community to participate actively in the life of the city.

The Lycée received private funding for this project, but raised the full amount of the large budget required by selling its property (USD 60 million) and issuing taxexempt bonds (USD 95 million). Even though the tuition fees had to be increased, they are still 30\% lower than the fees charged by private schools in New York. Some 120 pupils receive full or partial scholarships. Some other characteristic features of the Lycée are its bilingual education, which follows the curriculum of French lycées, and its diverse student body with over 50 nationalities - an openness to the world that Descartes would no doubt have appreciated. France's President, Jacques Chirac, came in person to inaugurate the Lycée in September 2003, proving that this distinctive institution is indeed a showcase for France and the French-speaking community in New York.

\section{Article by:}

Florence Michel

24 rue du Poitou, 75011, Paris, France

Tel.: 33 (0)6 07368216

E-mail: scribat.fm@noos.fr

\section{A BUILDING DEVELOPMENT PLAN AT LAVAL UNIVERSITY, QUEBEC}

Laval University is launching a series of major development projects aimed at meeting the needs of an institution that currently offers over 350 academic programmes to more than 36000 students. It also ranks among the top ten Canadian universities in terms of research. Between now and the spring of 2005, nearly 130 million Canadian dollars will be invested in campus infrastructure, bringing total investment in this field since 1990 to some CAD 300 million. The administrators responsible for this construction say that the these building projects will literally transform the landscape of their university and will have many positive side effects that will have a major impact not only on the university community, but also on the Quebec region and society as a whole, since they will make it possible to house multi-disciplinary research teams under a single roof.

This article will focus on three of the most important construction projects that are already under way or about to start: the Wood Processing Centre, the Optics, Photonics and Laser Centre, and Ferdinand-Vandry Hall. A brief history of the Laval University campus is provided at the end of this article.

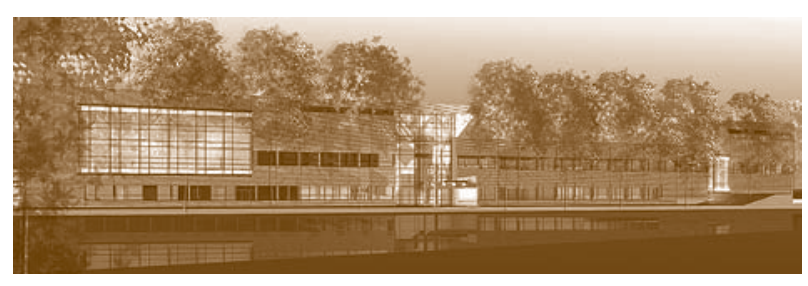

The Wood Processing Centre (CTBO)

\section{The Wood Processing Centre}

Work on the Wood Processing Centre (Centre de transformation du bois ouvré, CTBO) began on 18 September 2003 and will continue until early 2005.

With its state-of-the-art technological facilities, the CTBO will become both a research centre that is unique in Canada and a Pan-Canadian education and training centre. What is more, this centre, which the representatives of Laval University describe as being the only one of its kind in the world, will be built entirely of wood 
The Sainte-Foy Campus from the air

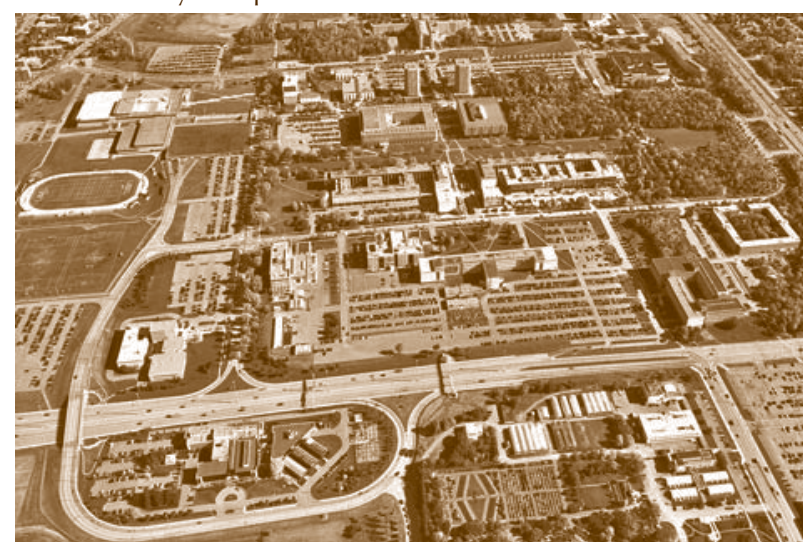

The future Optics, Photonics and Laser Centre (COPL)

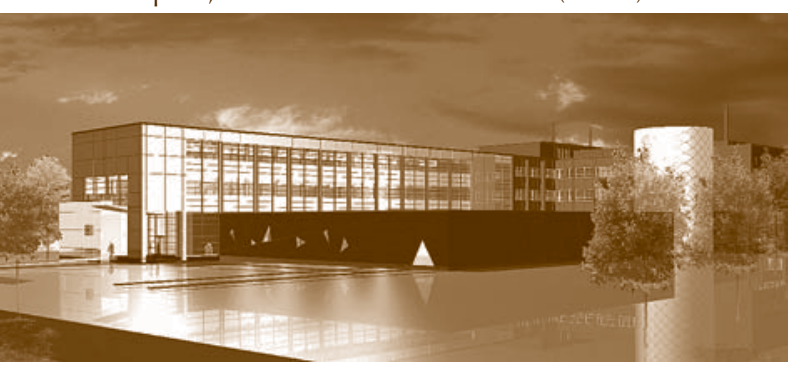

and will have some $5000 \mathrm{~m}^{2}$ of floor space. It was designed, in collaboration with Laval University's Faculty of Planning, Architecture and Visual Arts, to meet the criteria for a building based on sustainable development principles, and is the first of its kind built on campus. The use of natural energy sources will be optimised, and the energy produced will be recycled so that this new building will need little or no additional energy. The building will become a showcase highlighting the diversity of Canadian wood products.

This facility will not only be used for education, but will house basic and applied research activities on the development of value-added wood processing, such as jointed wood, glue-laminated beams, wood floors and roof beams. It will have some 20 specialised laboratories for researchers in the field of wood sciences, wood processing technologies and silviculture.

The new facility will have many significant side benefits since there are very few centres devoted to these research sectors in the world. This project will make a major contribution to the economic development of Quebec and its regions and will act as a real driver of innovation to meet the main challenges facing the wood industry.

Lastly, it should be pointed out that this project is a key component of a Pan-Canadian consortium comprising Laval University, the University of British Columbia, the University of New Brunswick and Forintek (Eastern Laboratory and Western Laboratories).

\section{The Optics, Photonics and Laser Centre}

This coming spring, work will also begin on the new Optics, Photonics and Laser Centre (Centre d'optique, photonique et laser, COPL). It will be the largest education and research centre in the field of optics-photonics in Canada. The construction of the new building will provide the COPL's researchers with cutting-edge research facilities in this field. Many laboratories will have dust-controlled clean-rooms for the micro-manufacturing of photonics components. A substantial share of the costs of this building will go to the construction of a laboratory for manufacturing and characterising optical fibres. Two 12-meter draw towers for manufacturing optical fibres will also be built.

This grouping of researchers in the field of optics-photonics will reinforce synergies with industry through closer contacts with industry researchers, which will promote collaborative projects using the new physical infrastructure and the new equipment it contains. It will enable Laval University and the Quebec region to become the main centre for cutting-edge research and the education of highly-skilled staff in the field of optics-photonics in Canada.

\section{Ferdinand-Vandry Hall}

Lastly, the third but not the least ambitious project comprises the renovation of Ferdinand-Vandry Hall, also known as the Medicine Building, which will be brought up to standards, refitted and enlarged.

This is the last of Laval University's older buildings to be renovated. More will be invested in this project alone than in the two preceding projects together, as a total amount of some CAD 65 million will be required. The building will be expanded by some $20000 \mathrm{~m}^{2}$ to cater for the faculties of medicine, pharmacy and nursing sciences. This will also make it possible to accommodate the health science units currently housed in other campus buildings. The consolidating of all health sciences within a single centre - medicine, nursing sciences, pharmacy, physical and occupational therapy, social and preventive medicine and other specialties — will be a first in North America in this field.

More specifically, the consolidation of education in the health sciences will help ensure that the university provides state-of-the-art training to health professionals serving the Québec-Chaudière-Appalaches region and Est-du-Québec regions.

At the time of writing, the starting and ending dates for this project have not yet been set. 


\section{History of the campus}

The first French-speaking university in North America, Laval University is located in the heart of Quebec's capital, a UNESCO world heritage city. At the time of its foundation in 1852 by Bishop François de Laval, the university was located in the district recognised today as a UNESCO site. These buildings, known as the Seminary of Quebec, occupy part of the Cap Diamant promontory near the Château Frontenac, a luxury hotel with a worldwide reputation. In 1878, Laval University opened a "branch" in Montreal which in 1920 became the University of Montreal.

In the early 1950s, due to the expansion of the city of Quebec, Laval University moved out of "Old Quebec" into the suburbs. This move to Sainte-Foy promoted the spectacular development of this city at that time. Later, wishing to follow the trend of the population moving back to the city centre, in 1988 Laval University transferred its architecture school to one of the buildings of the Old Seminary, returning to its roots through the highly symbolic choice of this school.

Laval University undertook a major building campaign between 1962 and 1970, when seven large buildings were constructed, including one of the high-rise buildings housing the Faculty of Education Sciences.

Since 1990, there has been a second wave of construction at Laval University, with new buildings being constructed and others undergoing major renovation and enlargement.

To see the extent of the work under way or soon to begin on the campus, consult the Internet site: www.ulaval.ca/ chantiers/

For further information, contact:

Gilles Daoust, Directeur du service des immeubles

Université Laval, Quebec, Canada

Tel.: 1418656 2131, p2870

E-mail: gilles.daoust@si.ulaval.ca

A summary of investments at Laval University since 1990, including work in progress

$\begin{array}{lll}\text { Description } & \text { Building } & \text { Amount (CAD million) }\end{array}$

\section{Since 1990}

Community, Cultural and Administrative Services

Greenhouse Production Complex

Horticultural Research Centre

Industrial and Economic Relations

Continuing Education Centre

Nutraceuticals and Functional Food Institute

Visual Arts School

Ball-Bearing Workshop

Administration Sciences (enlargement, refitting and renovation)

Science and Engineering Faculty (enlargement, refitting and renovation)

Molecular Biology Research Laboratories

Addition of a Magnetic Resonance Laboratory

Addition of an Aquatic Sciences

Research Laboratory
Alphonse-Desjardins/Maurice-Pollack

34.60

Envirotron

1.40

Envirotron

7.60

J.-A.-De Sève

La Laurentienne

15.60

INAF

19.00

La Fabrique $\quad 8.90$

La Fabrique $\quad 0.60$

Palasis-Prince $\quad 26.30$

Adrien-Pouliot 33.40

Charles-Eugène-Marchand $\quad 19.20$

Charles-Eugène-Marchand $\quad 1.20$

Charles-Eugène-Marchand $\quad 2.25$

Subtotal: 170.05

\section{In progress}

Water cooling plant (new building)

Centrale d'eau refroidie

7.80

Wood Processing Centre (new building)

СТВО

25.00

Optics, Photonics and Laser Centre

COPL

(new building for 2005)

Health Sciences (upgrading and enlargement Pavillon Ferdinand-Vandry of the faculties of Medicine, Pharmacy and Nursing Sciences)
65.00

Subtotal: 129.80

GRAND TOTAL: 299.85 